\title{
Erratum to: Risk factors in cutout of sliding hip screw in intertrochanteric fractures: an evaluation of 937 patients
}

\author{
Kuang-Kai Hsueh • Chi-Kuang Fang • \\ Chuan-Mu Chen • Yu-Ping Su • Heng-Fei Wu • \\ Fang-Yao Chiu
}

Published online: 13 November 2011

(C) Springer-Verlag 2011

Erratum to: International Orthopaedics

DOI 10.1007/s00264-009-0866-2

The stated country of the affiliation section of the original version unfortunately contained an error. The correct version is given below.

The online version of the original article can be found at http://dx.doi. org/10.1007/s00264-009-0866-2.

K.-K. Hsueh • C.-K. Fang • C.-M. Chen · Y.-P. Su • H.-F. Wu •

F.-Y. Chiu $(\bowtie)$

Departments of Orthopaedics \& Traumatology, Taipei Veterans

General Hospital, National Yang-Ming University,

201, Sec 2, Shih-Pai Road,

Taipei 112 Taiwan, Republic of China

e-mail: fychiu@vghtpe.gov.tw 